\title{
Imprecisão conceitual e pulverização dos recursos federais na Função Assistência Social*
}

\author{
IVANETE BOSCHETT|** \\ SANDRA OLIVEIRA TEIXEIRA ${ }^{* * *}$
}

\begin{abstract}
Resumo: O texto analisa o gasto federal brasileiro da 'Função Assistência Social', conforme classificação do Orçamento Geral da União, no período de 1994 a 2001. Duas situações foram constatadas: a pulverização dos recursos em diversas unidades orçamentárias, sem uma correspondente articulação com os mecanismos do sistema descentralizado e participativo da assistência social; e a outra, o equívoco na concepção de assistência social, o que ocasiona a dispersão do recurso em ações que não tem caráter assistencial. São situações que contribuem para descaracterizar a política de assistência social, transformando-a em território indefinido e passível de ser capturada por todo e qualquer interesse clientelista.
\end{abstract}

Palavras-chave: Assistência social, orçamento público, financiamento.

\begin{abstract}
This analysis aims at measuring the expenditure of the Brazilian federal government on the area of social assistance, according to directions given by the Federal General Budget, between 1994 and 2001. The text focuses two current events which still have traces of the past: the former is the bad distribution of financial resources into different budgetary units, in disagreement with the mechanism of participation and decentralization of the social assistance system. The latter is the misconception about what social assistance is, which caused the expenditure of those financial resources on non-social assistance areas. These two events have contributed to the deviation of the social
\end{abstract}

* Este artigo resultou de trabalho de consultoria à DISOC/IPEA na pesquisa "O Financiamento das Políticas Sociais no Brasil na Década de 90", concluído em junho de 2002.

${ }^{* *}$ Assistente Social, professora adjunta do Departamento de Serviço Social e Programa de Pós-graduação em Política Social da UnB. Pesquisadora do CNPq. E-mail: ivanete@unb.br

*** Assistente Social, mestranda no Programa de Pós-graduação em Política Social da UnB. Bolsista do CNPq. E-mail: sandraot@unb.br 
assistance policy from its original standard turning it into an unclear and indefinite field which became an easily captured target by client interests.

Key-words: Social Assistance, public budget, financing.

\section{Introdução}

A inclusão da assistência social no sistema de seguridade social brasileiro, além de reconhecer esta política como direito social, materializou a possibilidade de instituição de um espaço orçamentário próprio. Antes da aprovação da Lei Orgânica de Assistência Social (LOAS), em 1993, inexistia na estrutura orçamentária da União, Estados e Municípios uma rubrica específica para financiamento das ações assistenciais. Predominava um quadro de desarticulação, fragmentação, pulverização e ausência de planejamento fiscal, o que condicionava a execução das ações à existência de sobras orçamentárias.

Ao instituir o Fundo Nacional de Assistência Social (FNAS), em 1995, a LOAS criou um mecanismo de acompanhamento e controle da trajetória dos recursos previstos e aplicados na área, o que possibilita estabelecer uma gestão transparente dos recursos públicos, que deve obedecer às diretrizes da Política Nacional de Assistência Social (PNAS) e deve ser aprovada e fiscalizada pelo Conselho Nacional de Assistência Social (CNAS).

Por outro lado, as particularidades da área de assistência social conferem a esta política a condição de configurar-se como política social setorial específica regida pela LOAS e, ao mesmo tempo, constituir-se como ação ubíqua, presente em praticamente todas as outras políticas sociais, como mecanismo de viabilização de acesso a estas políticas (Pereira, 1996). Estas ações, entretanto, não se regem pelo disposto na LOAS. Tem-se, como exemplos, na saúde, as ações de distribuição de medicamentos, bolsa-alimentação, aparelhos de órtese e prótese e passes para transporte coletivo; na educação, a distribuição de material didático, merenda escolar e, recentemente, os programas de bolsa-escola; na previdência, benefícios como renda mensal vitalícia, salário família, auxílio natalidade e auxílio funeral (estes últimos transferidos para a área da assistência social com a LOAS, mas ainda não implementados). Também outros programas, alocados em outros ministérios, são classificados como de assistência social, ainda que sua natureza assistencial seja discutível, conforme será observado adiante. 
Quando se procede a um mapeamento das ações federais classificadas na "Função Assistência" e/ou designadas sob este termo na classificação funcional programática do poder executivo, comprova-se a forte ubiquidade desta política social e, ao mesmo tempo, depara-se com a dificuldade teórico-metodológica de delimitar o escopo do financiamento a ser analisado. Independente das polêmicas e questionamentos sobre a natureza assistencial de todas as ações classificadas na "Função" ou "Subfunção" Assistência, o fato é que um estudo que intenciona conhecer a estrutura de financiamento desta política social no âmbito federal não pode ficar alheio à destinação dos recursos públicos federais para esta função, independente de seu locus institucional.

Até 1999, a assistência situava-se, na classificação orçamentária, ${ }^{1}$ na "Função 15", juntamente com a previdência social. Esta função comportava quatro programas, sendo um a assistência social, sob a rubrica 081, com cinco subprogramas: assistência ao menor (0483), assistência ao silvícola (0484), assistência à velhice (0485), assistência social geral (0486) e assistência comunitária (0487). Os outros três programas da Função 15 eram: previdência (082), programa de integração social (083) e programa de formação do patrimônio do servidor público (084).

Com a reestruturação da classificação orçamentária em $2000,{ }^{2}$ a assistência passa a ter uma rubrica específica - Função 08 desdobrando-se em quatro subfunções: assistência ao idoso (241); assistência ao portador de deficiência (242); assistência à criança e ao adolescente (243); e assistência comunitária (244). Cada uma destas subfunções abrange diversos projetos e atividades. Tais classificações, mais que simplesmente propiciar o arranjo orçamentário e classificatório dos recursos públicos, denotam quais são as ações assistenciais financiadas com recursos federais e trazem implícita a concepção de assistência social assumida pelo Poder Executivo.

Assim, quando se verificam quais foram as ações que receberam recursos federais sob a rubrica assistência social entre os anos 1994 e 2001, constata-se que, sob esta designação, alojamse uma série de programas e projetos que não seguem e nem se

${ }^{1}$ Cf. MPO/SOF. Orçamento Federal. Orçamento da União. Orçamentos Fiscal e da Seguridade Social. Exercícios de 1993 a 1999.

2 Cf. MOG/SOF. Manual Técnico de Orçamento. Instruções para Elaboração da Proposta Orçamentária da União MTO-02, 2000. Anexo da portaria/SOF n. 42 de 14 de abril de 1999. D.O.U, Brasília, 15, abr. 1999. 
submetem aos preceitos da legislação que regulamenta esta política: a LOAS. Sem entrar no mérito se estas ações elevem ou não ser considerados como assistência social, não se pode, contudo, deixar de considerar que muitas delas, tidas pela ótica do financiamento como de "assistência social", não entram no circuito estabelecido pela LOAS, não seguindo, assim, suas regras e nem submetendose à análise e ao controle do CNAS. Por outro lado, também revela que as análises sobre a assistência social não podem se restringir às ações financiadas com recursos do FNAS, sob o risco de se excluir ações típicas de assistência social implementadas por diversos ministérios.

A identificação das ações que, historicamente, recebem recursos públicos sob a designação assistência social, revela a dimensão do problema a ser enfrentado, ao mesmo tempo em que indica pistas para seu enfrentamento, no sentido de melhor delimitar e estruturar o financiamento das políticas públicas. Nesse sentido, tomando por base a classificação funcional e utilizando os dados do Sistema Integrado de Dados Orçamentários (SIDOR) é possível identificar todos os projetos e atividades que recebem recursos federais na Função Assistência. Vários recortes analíticos são possíveis.

Um deles permite identificar as ações que, na funcional programática, estão incluídas ou na Função, ou na Subfunção, ou nos Projetos/Atividades da Assistência. Neste caso, não são consideradas ações típicas de assistência porque se inserem em um ou em outro código e não em todas as rubricas da Função Assistência. Assim, as ações recebem recursos oriundos da Função Assistência, mas podem estar inseridas em outras Funções, ou outras Subfunções, referentes às diversas áreas, como educação, saúde, previdência, trabalho, cultura, urbanismo, habitação, dentre outras. Esta classificação é designada, comumente, de "conceito histórico". ${ }^{3}$

Outro recorte possível refere-se apenas aos recursos destinados às ações assistenciais que, na funcional-programática, estão classificadas simultaneamente na Função e Subfunções Assistência (a partir de 2000) ou no Programa e Subprogramas Assistência (até 1999). São reconhecidas pelo aparato governamental como ações típicas de assistência social e incluem todas aquelas

3 Este é o enfoque adotado na análise de Cordeiro, publicada na revista Serviço Social e Sociedade, n. 62, mai. 2000. 
que recebem recursos do FNAS, além de outras, como se verá a seguir. Do ponto de vista institucional, podem estar vinculadas a qualquer órgão público.

Um terceiro recorte analítico é aquele que considera, de modo mais restrito, apenas os recursos destinados ao Fundo Nacional de Assistência Social (FNAS). Neste caso, constam apenas as ações cujos recursos são repassados a Estados e Municípios via FNAS, elevem constar na PNAS e devem ser submetidos à análise e aprovação do CNAS, conforme determina a LOAS. Este último recorte, portanto, baseia-se no locus institucional da ação e menos na sua função enquanto política pública.

Para este estudo adotou-se o segundo enfoque analítico exposto acima, o que resultou em três recortes metodológicos. $\mathrm{O}$ primeiro refere-se à análise exclusiva da Função Assistência Social, conforme classificação do Orçamento Geral da União (OGU), e que, portanto, tem um enfoque direcionado para as ações desenvolvidas no âmbito do governo federal. Não foram analisadas ações de outras funções, o que levaria à classificação conhecida como conceito histórico. Diante das mudanças realizadas na classificação orçamentária em 2000 , prosseguiu-se à seguinte delimitação: entre 1994 e 1999, a identificação dos projetos e atividades que receberam recursos foi efetivada levando em conta ações assistenciais que se encontram simultaneamente classificadas na Função Previdência e Assistência Social (15) e Programa Assistência Social (08); e, em 2000 e 2001, considerou-se apenas as ações classificadas na Função Assistência Social (08). Os dados relativos aos recursos são oriundos do Sistema Integrado de Administração Financeira (SIAFI) e Sistema Integrado de Dados Orçamentários (SIDOR), disponibilizados pela Diretoria de Políticas e Estudos Sociais (DISOC) do Instituto de Pesquisa Económica Aplicada (IPEA), deflacionados mês a mês pelo IGP-DI, a preços de dezembro de 2001.

\section{O ajuste neoliberal brasileiro e as implicações no orçamento da seguridade social}

O Estado Democrático de Direito no Brasil é instituído legalmente no final da década de 80 , em momento de avanço do neoliberalismo na América Latina (Anderson, 1995). A Constituição Federal de 1988 é exemplo seminal das conquistas obtidas 
legalmente na área social, mas que não foram completamente implementadas. Os governos seguintes, sobretudo o período Fernando Henrique Cardoso, canalizaram suas políticas econômicas para a liberalização e desregulamentação do mercado, a estabilização monetária e o combate à inflação, conforme o modelo proposto pelo Monetário Internacional e pelo BFundoanco Mundial (Soares, 2000). Para muitos analistas, tal política, ao contrário das expectativas prevalecentes no final da década de 80, levou ao "desmonte da nação" (Lesbaupin, 2000; Biondi, 1999).

A opção política foi pelo enfraquecimento da função social do Estado brasileiro e fortalecimento de seu papel no provimento das condições necessárias à expansão do capital financeiro, o que trouxe sérias consequências econômicas e sociais. Uma delas foi a política deliberada de juros altos em detrimento da opção pelo investimento produtivo e pela tributação da riqueza, o que custou o endividamento acelerado do Estado. A dívida pública cresceu espantosamente, o que tem implicações negativas para o financiamento das políticas sociais. Conforme divulgado no Correio Braziliense (26 jul. 2002, p. 8), no início do Plano Real, a dívida pública líquida representava $30,4 \%$ do Produto Interno Bruto; em dezembro de 1998, já equivalia à $50,7 \%$ do PIB; em setembro de 2001 , alcançou $54,7 \%$ do PIB; e, em junho de 2002 , atingiu $58,6 \%$ do PIB.

Além disto, verifica-se um retrocesso em avanços sociais históricos, com a desregulamentação das relações de trabalho, o que tem agravado a informalidade e sua consequente redução de direitos. Também predominaram antigos problemas, como o retorno de doenças que estavam sob controle (dengue, febre amarela) e a precarização da infra-estrutura pública (Soares, 2000).

A ofensiva neoliberal agravou profundamente o quadro social brasileiro desencadeando aumento na demanda por políticas sociais e, simultaneamente, defendendo a contenção de gastos sociais. O governo brasileiro, ao adotar o modelo de estabilização monetária, com o objetivo primeiro de efetuar o pagamento dos empréstimos internacionais e da dívida interna, coloca em risco a consolidação do sistema de seguridade social, visto que as imposições de manutenção de elevado superavit primário pelo FMI vêm provocando a utilização de parte do orçamento da seguridade social para o pagamento da dívida, sobretudo os recursos oriundos das contribuições sociais (Anfip, 2002). A austeridade do ajuste fiscal também se revela na prática usual de contingenciamento dos 
programas sociais, o que permite ao governo limitar a execução dos recursos aprovados na LDO e realocá-los em rubricas destinadas ao pagamento dos juros da dívida pública (Miranda, 1999).

Conforme mostrou Dain (1998), as projeções de gastos com a seguridade social, ainda em 1994 até o ano 2000, "indicavam que, caso fossem implementados todos os benefícios previstos, mantida a vinculação de $30 \%$ dos gastos à saúde e efetivamente destinadas aos programas as fontes de receitas criadas para estes fins, o sistema teria um déficit não superior a $0,5 \%$ do PIB, se a economia crescesse ataxas anuais de 4\%" (Dain, 1998, p. 27). A autora afirma ainda que o atual desempenho da arrecadação tributária permitiria a eliminação desse déficit.

Contudo, a integração das três políticas de seguridade num orçamento unificado tornou-se fictícia. O orçamento da seguridade social existe somente na identificação do Orçamento Geral da União para efeito de divisão e transparência a partir de um elemento identificador nas rubricas (esfera 20 para o orçamento fiscal, e esfera 30 para o orçamento da seguridade social). Na prática, permanece uma acirrada disputa de recursos entre as três políticas e uma resistência feroz da previdência em partilhar os recursos das contribuições sociais com a saúde e a assistência (Piscitelli et al. 2002). Dados divulgados pela Anfip (2002), relativos a 2001, revelam que a assistência (incluindo a Renda Mensal Vitalícia, Fundo Nacional de Assistência Social e Assistência Social Geral) ficou com 4,7\% dos recursos gastos nesse ano com as políticas de seguridade social, enquanto a saúde recebeu $15,7 \%$ e a previdência (pública federal e RGP) absorveu 79,6\% (Boschetti, 2003).

Segundo a própria Anfip (2002), e também outros analistas, como Fraga (2000) e Paiva \& Rocha (2001), uma das principais implicações do ajuste neoliberal para a seguridade social é a realocação das fontes oriundas das contribuições sociais (Cofins, CSLL e CPMF) pelo Tesouro Nacional, por meio da Desvinculação das Receitas da União (DRU), antigo Fundo de Estabilização Fiscal (FEF). ${ }^{4}$ Nestas fontes, os recursos desvinculados em 2001 chegaram a $30 \%$ do total arrecadado, o que implicou na redução de recursos

4 A Desvinculação de Receitas da União foi criada em 1999 pela proposta de Emenda Constitucional $n^{\circ} 85 / 99$, para vigorar no período entre 2000 e 2003 , e prevê que $20 \%$ da arrecadação de impostos e contribuições sociais da União podem ser desvinculados de órgão, fundo ou despesa, o que na prática, possibilita redirecionar $20 \%$ da arrecadação que, constitucionalmente, deveria ser aplicada na seguridade social. Cf. Fraga (2002). 
da seguridade social. Comparando as áreas que receberam recursos destas três fontes, criadas para diversificar a base de financiamento da seguridade social, constata-se que, em 2001, apenas $50 \%$ da Cofins, $21 \%$ da CSLL e $62 \%$ da CPMF foram aplicados nas políticas que compõem a seguridade social (saúde, previdência e assistência social). O restante foi aplicado em outras áreas ou ficou retido no Tesouro Nacional (Boschetti, 2003). Diversas análises (Anfip, 2002; INESC, 2001; Fraga, 2000) já enfatizaram que os recursos retidos pelo Tesouro Nacional são utilizados para manter o superavit primário e pagar os juros da dívida pública. ${ }^{5}$ Em 2001, $R \$ 36.145$ bilhões arrecadados destas fontes não foram gastas com a seguridade social.

A questão do financiamento vem sustentando os argumentos da reforma da previdência, seja aquela já realizada durante o Governo FHC (Salvador \& Boschetti, 2002), seja as propostas em curso apresentadas pelo Governo Lula. Das três políticas, a que sofre maior prejuízo é, sem dúvida, a assistência social, seja pela dificuldade histórica de ser reconhecida como direito social, seja pela forte permeabilidade às manobras políticas que a transmutam em ações assistencialistas e clientelistas, seja pela fragmentação dos recursos a ela destinados conforme será demonstrado a seguir.

\section{Ubiquidade e especificidade da Assistência Social}

Conforme determinado no artigo 195 da Constituição Federal de 1988, as ações governamentais na área de assistência social passam a ter fontes de receitas definidas, discriminadas no orçamento da seguridade social. A inexistência de fundos específicos e de fontes de financiamento foi, historicamente, uma das causas da insuficiência dos recursos, pois sem garantia orçamentária, a assistência sempre ficava com as sobras dos recursos constituindo-se como a "prima pobre" do orçamento (Teixeira, 1997). A LOAS modifica esta situação de inexistência de fundos públicos específicos e estabelece que os recursos da União destinados à assistência social serão repassados ao FNAS. É importante atentar, conforme alerta Cunha (2000, p. 100), que "o fundo não é uma entidade jurídica, órgão ou unidade orçamentária, mas um conjunto de contas que identificam as origens e as aplicações de recursos de um determinado objetivo, serviço ou

5 A esse respeito o jornal Folha de São Paulo publicou em 8 de fevereiro de 2003: "Economia do Governo vai para o pagamento de juros", mostrando que em 2002 o setor público (União, Estados e municípios) gastou $R \$ 113.978$ bilhões com pagamento de juros da dívida pública (interna e externa), p. B-4. 
política pública". A autora ressalta, ainda, que o fundo passa a ser "instrumento permanente e responsável pela gestão dos recursos de toda uma política, não só de programas ou ações pontuais" (Cunha, 2000, p. 100).

O Decreto $n^{\circ} 1.605 / 95$, que criou o FNAS, estabelece que sua estrutura orçamentária deverá contemplar as políticas e programas anuais e plurianuais do governo, o que sugere que todos os recursos definidos sob a rubrica assistência social, mesmo aquele não executados institucionalmente pelo ministério responsável pela área, ${ }^{6}$ deveriam estar previstos na PNAS e serem geridos pelo FNAS, 0 que exigiria a articulação de todos os ministérios que executam ações assistenciais na definição da proposta orçamentária anual. Em determinados momentos, o texto do decreto parece deixar claro que todo o recurso destinado aos programas de assistência social do governo (o que pressupõe inclusive aqueles localizados nos Ministérios de Saúde, Educação, Previdência, e outros) deveria constar da PNAS, ser aprovado pelo CNAS e passar pelo FNAS. Tal orientação parece seguir a preocupação de organização do gasto social por área de atuação e não sob o critério institucional ou funcional, conforme ressaltado em análise de Ribeiro e Fernandes (2000). Por outro lado, ao definir onde os recursos do FNAS devem ser aplicados, o mesmo decreto restringe esta perspectiva mais ampla e mantém, ainda que não de maneira explícita, as ações implementadas por outros ministérios fora das determinações legais estabelecidas neste decreto e na LOAS.

Observa-se que somente as ações definidas na PNAS, normatizadas e coordenadas institucionalmente pelo ministério responsável pela assistência, e que recebem recursos via FNAS, submetem-se aos princípios e diretrizes de descentralização e controle social previstos na LOAS. Já as ações assistenciais desenvolvidas por outros ministérios não precisam seguir estas diretivas. Ainda é possível argumentar que o artigo 18 da LOAS, em seu inciso II, atribui como uma das competências do CNAS a normatização das ações na área da assistência social, o que não significa que devam ser ações exclusivamente elaboradas pelo ministério responsável pela área. Entretanto, este mesmo artigo, no inciso VIII, restringe sua competência à análise, apreciação e aprovação somente da proposta orçamentária da assistência social encaminhada pelo órgão responsável pela PNAS.

É interessante notar que o FNAS, em conjunto com a PNAS e o CNAS, constituem uma tríade estratégica para tornar visível e 
consolidar a assistência social no espaço da administração pública, na medida em que se baseiam na concepção de direito social e vislumbram a integração dos programas de forma a evitar a desarticulação e o paralelismo de ações. E isto porque o FNAS possibilita a gestão transparente dos recursos financeiros, ao passo que a PNAS apresenta as diretrizes norteadoras da assistência social e, juntamente com o CNAS, permite a participação e o controle da população sobre as ações assistenciais públicas e privadas.

É reconhecida a necessidade de um locus institucional próprio para a política de assistência social, visto que trata-se de uma política social com diretrizes e objetivos próprios. Mas isto não significa que esta não deva ser concebida como integrante de um sistema mais amplo de proteção social, o que torna indispensável sua articulação com as demais políticas sociais governamentais. Enquanto política com identidade própria apresenta como característica peculiar a capacidade de realizar a unidade das demais políticas sociais em função das diversas dimensões do atendimento das necessidades humanas básicas. É patente a transversalidade (Sposati et ai., 1986), ou para dizer de outra forma, é inequívoca a presença e participação ativa da assistência em todas as políticas sociais e económicas (Pereira, 1996). A assistência constitui-se em condição necessária para que estas políticas não se restrinjam à sua especialização e para evitar a elitização das mesmas, que tendem a pautar-se por critérios que privilegiam a exclusão social (Pereira, 1998).

Considerando esta sua posição estratégica, ou seja, seu caráter específico mas também ubíquo, a análise apresentada a seguir mostra as ações que se encontram classificadas na função assistência social, independente de seu locus institucional. Até o momento, sabe-se que há um leque de ações classificadas na função assistência, mas desenvolvidas por várias unidades orçamentárias, as quais não têm seus recursos alocados no FNAS e nem se submetem ao controle do CNAS. Tais ações são, frequentemente, manuseadas politicamente sob a forma de assistencialismo, e sua condição de política de seguridade social é desconsiderada. Ao invés de serem ressaltadas como ações que objetivam "de forma gratuita e desmercadorizada, contribuir para a melhoria das condições de vida e de cidadania da população pobre" (Pereira, 2000, p. 225226), são frequentemente confundidas e tratadas como uma ação moral, paliativa, compensatória e/ou clientelista, o que tem levado

6 Até dezembro de 2002, o órgão responsável pela assistência era a Secretaria de Estado de Assistência Social do MPAS. A MP n ${ }^{9}$ 103, de 01/01/2003 extinguiu a SEAS e criou o Ministério da Assistência Social. 
ao uso degenerado e indiscriminado na elaboração dos serviços, programas e projetos (Pereira, 1996).

\section{A totalidade dos recursos federais destinados à Função Assistência Social}

A lentidão no processo de regulamentação da assistência social e dos seus mecanismos de financiamento permitiu a alocação dos recursos no FNAS somente a partir de 1996. Mesmo após a implementação deste fundo, constata-se que o recurso federal gasto na Função Assistência Social encontra-se disperso em diversas unidades orçamentárias.

ATabela 1 mostra a evolução crescente do montante de recurso executado na Função Assistência Social, que passou de R\$ 602 milhões, em 1994, para $R \$ 3,6$ bilhões em 1998 e $R \$ 5,2$ bilhões em 2001. Ao verificar o percentual anual de crescimento dos recursos, constata-se que foi executado em cada ano um montante superior ao ano anterior. No entanto, a maioria dos anos apresenta acréscimo de recursos inferior ao realizado no ano anterior, sendo que o crescimento de 1996 para 1997 foi de 106\%, o que se explica pelo efetivo funcionamento do FNAS a partir deste ano.

\section{Tabela 1 - Montante e Percentual de Crescimento do Recurso Federal} Executado na Função Assistência Social por ano -1994/2001

\begin{tabular}{c|c|c}
\hline Anos & Recurso Executado & \% de Crescimento \\
\hline 1994 & 602.391 & 49,52 \\
\hline 1995 & 900.736 & 27,47 \\
\hline 1996 & 1.148 .131 & 106,81 \\
\hline 1997 & 2.374 .512 & 55,07 \\
\hline 1998 & 3.682 .273 & 12,89 \\
\hline 1999 & 4.167 .907 & 22,83 \\
\hline 2000 & 5.099 .669 & 2,68 \\
\hline 2001 & 5.240 .050 & \\
\hline
\end{tabular}

Fonte: SIAFI/SIDOR disponibilizado pela DISOC/IPEA. Em R\$ $1.000,00$ a preços de dez./2001, deflacionados mês a mês pelo IGP-DI. Elaboração própria. 
Mesmo após a implementação do FNAS, permaneceu a dispersão de recursos federais executados na Função Assistência Social em várias unidades orçamentárias, ou seja, em vários ministérios, como será demonstrado a seguir. Com base na organização e comparação dos recursos a partir de sua origem, ou seja, a partir de sua esfera orçamentária, bem como seu destino, é possível verificar de onde provêm os recursos, se do orçamento fiscal ou do orçamento da seguridade social, bem como identificar para onde os mesmos estão sendo destinados, como revela a Tabela 2.

\section{Tabela 2 - Recurso Federal Executado na Função Assistência Social Segundo a Origem Orçamentária}

\begin{tabular}{c|c|c|c|c|c|c|c}
\hline \multirow{2}{*}{ Ano } & \multicolumn{2}{|c|}{$\begin{array}{c}\text { Orçamento } \\
\text { Fiscal* }\end{array}$} & \multicolumn{2}{c|}{$\begin{array}{c}\text { Orçamento da Seguridade } \\
\text { Social Aplicado no FNAS }\end{array}$} & \multicolumn{2}{c|}{$\begin{array}{c}\text { Orçamento da Seguridade } \\
\text { Social Aplicado em Outros } \\
\text { Ministérios }\end{array}$} & \multirow{2}{*}{ Total } \\
\cline { 2 - 7 } & Montante & $\mathbf{\%}$ & Montante & $\%$ & Montante & $\%$ & \\
\hline 1994 & 40.257 & 6,68 & - & - & 562.134 & 93,31 & 602.391 \\
\hline 1995 & 77.868 & 8,64 & - & - & 822.868 & 91,35 & 900.736 \\
\hline 1996 & 49.703 & 4,32 & 938.077 & 81,70 & 160.351 & 13,96 & 1.148 .131 \\
\hline 1997 & 69.195 & 2,91 & 1.868 .664 & 78,69 & 436.653 & 13,38 & 2.374 .512 \\
\hline 1998 & 864.532 & 23,47 & 2.397 .244 & 65,10 & 420.497 & 11,41 & 3.682 .273 \\
\hline 1999 & 152.390 & 3,65 & 2.648 .952 & 63,55 & 1.366 .565 & 32,78 & 4.167 .907 \\
\hline 2000 & 19.172 & 0,37 & 3.249 .546 & 63,72 & 1.830 .951 & 35,90 & 5.099 .669 \\
\hline 2001 & 49.749 & 0,94 & 3.520 .988 & 67,19 & 1.669 .313 & 31,85 & 5.240 .050 \\
\hline
\end{tabular}

Fonte: SIAFI/SIDOR disponibilizado pela DISOC/IPEA. Em R\$1.000,00 a preços de dez/2001, deflacionados mês a mês pelo IGP-DI. Elaboração própria

* Não ocorreu alocação de recursos do orçamento fiscal no FNAS e nem no MPAS. Os recursos foram aplicados somente em outros ministérios.

A Tabela 2 permite uma visão geral dos recursos executados na função assistência segundo sua origem orçamentária. A primeira constatação é a predominância do orçamento da seguridade social no financiamento da assistência social, enquanto a participação do orçamento fiscal é ínfima, o que contraria o disposto na Constituição Federal.

Em relação especificamente aos recursos do orçamento fiscal que foram aplicados na função assistência, um primeiro aspecto que chama a atenção é a inconstância e a redução das transferências, 
sobretudo quando se compara o montante gasto ao total dos recursos aplicados na área, à exceção do ano 1998, quando ocorreu um importante aumento, que elevou a participação do orçamento fiscal a $23 \%$ do total dos recursos executados. O motivo deste aumento será analisado adiante.

Quanto ao orçamento da seguridade social, além de ser responsável por quase $100 \%$ do financiamento da área, com exceção de 1998, verifica-se que transfere recursos tanto para o FNAS, quanto para outros ministérios. A Tabela 2 evidencia que, após 1996, o FNAS tornou-se, efetivamente, o principal mecanismo de financiamento da assistência, ainda que o percentual de recursos executado venha diminuindo, em comparação ao total de recursos executado na função assistência. Por outro lado, vem ampliando os recursos da seguridade social repassados para outras unidades orçamentárias, sobretudo a partir de 1999, o que será objeto de análise posterior.

As análises seguintes buscam detalhar o destino dos recursos por esfera orçamentária, tendo o objetivo central de verificar quais são as ações financiadas com os recursos da função assistência, sobretudo aquelas que não recebem transferências via FNAS.

\section{Execução dos recursos destinados à Função Assistência Social procedentes do orçamento fiscal}

Conforme indica a Constituição Federal, no artigo 195, as ações que têm por objetivo assegurar os direitos concernentes à assistência social, à saúde e à previdência social devem ser financiadas com recursos procedentes do orçamento fiscal e da seguridade social. Porém, ao cruzar a análise da origem de recursos com a direção dos gastos, constata-se que os recursos do orçamento fiscal não foram utilizados para financiar o FNAS, tendo sido destinados às ações classificadas na função assistência social executadas por outros ministérios e/ou instituições.

O Ministério da Justiça é a unidade orçamentária responsável pela execução da maior parte dos recursos, em média com $77 \%$, na maioria dos anos, com exceção de 1998 e 2000, quando a Superintendência do Desenvolvimento do Nordeste (SUDENE) ficou 
com $94 \%$ e $58 \%$ dos recursos, respectivamente. Após um ano de vigência do FNAS, a partir de 1997, somente a Câmara dos Deputados, o Senado Federal, o Ministério da Justiça, a SUDENE e o Governo do Distrito Federal continuaram executando recursos da função assistência social. E depois da nova classificação, em 2000, com exceção da SUDENE, estas unidades orçamentárias foram excluídas, e ocorreu a inclusão do Instituto Brasileiro de Turismo, do Ministério do Orçamento e Gestão e do Gabinete da Presidência da República.

\section{Tabela 3 - Recurso Federal do Orçamento Fiscal Executado na Função Assistência Social por Ação -1994-2001}

\begin{tabular}{|c|c|c|c|c|c|c|c|c|}
\hline \multirow{2}{*}{ Ação } & \multicolumn{8}{|c|}{ Ano } \\
\hline & 1994 & 1995 & 1996 & 1997 & 1998 & 1999 & 2000 & 2001 \\
\hline Demarcação e regularização de terras & 5.470 & 13.216 & 13.224 & 16.620 & 4.167 & 19.699 & - & \\
\hline $\begin{array}{l}\text { Contribuição para a formação de patrimônio } \\
\text { do servidor público }\end{array}$ & - & 965 & 843 & - & - & - & - & \\
\hline Assistência à instituições privadas & 1.732 & 2.799 & 1.466 & 1.313 & 560 & 934 & - & \\
\hline Coordenação de assistência social & 6.689 & 5.754 & 5.856 & - & - & - & - & \\
\hline $\begin{array}{l}\text { Serviços administrativos da fundação de } \\
\text { amparo ao trabalhador preso }\end{array}$ & 895 & 1.096 & 1.570 & 1.314 & 890 & 994 & & \\
\hline Assistência à comunidades indígenas & 19.950 & 41.549 & 18.959 & 35.030 & 29.689 & 26.387 & & \\
\hline $\begin{array}{l}\text { Coordenação da politica de proteção a criança } \\
\text { e ao adolescente }\end{array}$ & - & - & - & & - & 333 & - & - \\
\hline $\begin{array}{l}\text { Assistência às comunidades indígenas } \\
\text { na faixa de fronteira norte }\end{array}$ & 204 & 51 & 85 & 40 & - & - & - & \\
\hline Proteção às florestas tropicais & - & - & - & 2.583 & 5.389 & 7.030 & - & \\
\hline Prestação de beneficio ao servidor público & - & 187 & - & - & - & - & - & \\
\hline Desenvolvimento de comunidades indígenas & 5.316 & 12.251 & 7.699 & 12.295 & 7.474 & 9.749 & - & - \\
\hline $\begin{array}{l}\text { Programa emergencial de frentes produtiva } \\
\text { no polígono das secas }\end{array}$ & - & - & - & - & 816.364 & - & - & \\
\hline $\begin{array}{l}\text { Ressarcimento das contribuições aos } \\
\text { pensionistas do extinto IPC" }\end{array}$ & - & - & - & - & - & 87.264 & - & - \\
\hline $\begin{array}{l}\text { Implant. de sistemas sanitário e de abast. de água } \\
\text { em escolas públicas }\end{array}$ & - & - & - & - & - & - & 11.212 & 39.819 \\
\hline Capacitação de gestores & & & & & & - & 6.170 & 3.064 \\
\hline Pesquisa de qualidade de vida - nacional & - & - & - & - & - & - & 990 & \\
\hline Campanha educativa de combate ao turismo sexual & & - & - & - & - & - & 799 & 668 \\
\hline $\begin{array}{l}\text { Implementação de projetos para o } \\
\text { desenvolvimento sustentáve }^{\star \star}\end{array}$ & - & - & - & - & - & - & - & 6.198 \\
\hline TOTAL & 40.257 & 77.868 & 49.703 & 69.195 & 864.532 & 152.390 & 19.172 & 49.749 \\
\hline
\end{tabular}

Fonte: SIAFI/SIDOR disponibilizados pela DISOC/IPEA. Em R $\$ 1.000,00$ a preços de dez/2001, deflacionados mês a mês pelo IGP-DI. Elaboração própria.

* Instituto da Previdência dos Progressistas

** Regiões: Alto Solimões, Fronteira do Mercosul, Águas Emendadas, Bacia do Itabapoana, Bico do Papagaio, Chapada das Mangabeiras, Chapada do Araripe, Vale do Jequitinhonha e do Mucuri, Vale do Rio Acre, Xingo, Entorno do DF, Metade Sul do RS, Zona da Mata Canavieira Nosdestina

A Tabela 3 mostra as ações classificadas na função assistência social que foram desenvolvidas pelas unidades orçamentárias citadas acima e receberam recursos do orçamento fiscal. Inicialmente, notase que após o ano de 2000, quando ocorreu a reorganização da classificação orçamentária, foram excluídas todas as ações até então 
classificadas nesta função e acrescidas novas ações. Dentre as 13 ações identificadas, apenas cinco foram classificadas nesta função desde 1994 até 1999: 'demarcação e regularização de terras indígenas', 'assistência às comunidades indígenas', 'desenvolvimento de comunidades indígenas', 'assistência a instituições privadas' e 'manutenção dos serviços administrativos da fundação de amparo ao trabalhador preso'.

Entre 1994 e 1997, a ação 'assistência às comunidades indígenas' consumiu a maior fatia de recursos, a qual destina-se ao atendimento indígena nas áreas de educação e saúde. Ainda na área indígena, foram incorporadas na função assistência social as ações 'proteção às florestas tropicais', que trata de cooperação técnica científica e tecnológica na área do meio ambiente; 'proteção e assistência às comunidades indígenas da faixa da fronteira norte', voltada para a demarcação de terras, ao apoio de atividades produtivas e a implementação de serviços educacionais e de saúde; e 'desenvolvimento de comunidades indígenas', que visa o desenvolvimento comunitário, mediante o uso de terras para fins agropecuários.

Em 1998, o 'programa emergencial de frentes produtivas no polígono das secas' executou o maior montante de recursos, com $\mathrm{R} \$ 816$ milhões, o que corresponde a $94 \%$ do total. Em 1999, foi o 'ressarcimento das contribuições aos pensionistas do extinto Instituto da Previdência dos Congressistas (IPC)' que absorveu a maioria dos recursos - 87 milhões (57\%). Esta ação deveria ser mantida com recursos da previdência social, visto que o IPC constituía-se em um regime previdenciário próprio dos deputados federais e senadores, que lhes permitia se aposentarem com, no mínimo, dois mandatos, ainda que suas contribuições ( $20 \%$ da folha de salários) não fossem suficientes para sustentar tal regime (Martins, 2000). Desse modo, recursos da Função Assistência serviram para sustentar o déficit deste regime específico de previdência.

As demais ações classificadas na função assistência social que receberam recursos oriundos do orçamento fiscal foram: 'contribuição para a formação de património ao servidor público', destinada a financiar o programa seguro-desemprego; 'prestação de benefício ao servidor público', responsável pelo pagamento de vale-transporte e vale refeição; 'coordenação de assistência social', que se refere à prestação de serviços assistenciais aos servidores civis e militares das forças armadas e seus dependentes; 'assistência a instituições 
privadas', responsável pela concessão de auxílio a entidades sem fins lucrativos para que possam cumprir suas funções filantrópicas, educativas e culturais; e a 'coordenação e manutenção da política de proteção à criança e ao adolescente', que tem por objetivo a defesa dos direitos destes segmentos, sobretudo aquelas preconizadas no Estatuto da Criança e Adolescente (ECA).

Nos anos 2000 e 2001, ainda segundo a Tabela 3, foram excluídas as ações até então predominantes, e incluídas cinco novas ações que, a rigor, não podem ser caracterizadas como específicas da assistência social: 'implantação de sistema sanitário e de abastecimento de água em escolas públicas', com a maior fatia dos recursos executados nos dois anos: $R \$ 11$ milhões (58\%) e $R \$ 39$ milhões (80\%), respectivamente; 'campanha educativa de combate ao turismo sexual'; e 'projetos para o desenvolvimento social', incluído nesta função orçamentária somente no ano de 2001, responsável pela execução de $R \$ 6$ milhões (12\%).

Existem, ainda, as ações 'capacitação de gestores', responsável pela execução de $R \$ 6$ milhões (32\%) e $R \$ 3$ milhões (6\%) nos anos 2000 e 2001 e 'pesquisa de qualidade de vida', classificada nesta função somente no ano 2000. Estas duas ações são atividades desenvolvidas no projeto Comunidade Ativa, implementado pelo Programa Comunidade Solidária. Analisando este programa, Silva (2001) enfatiza que este se caracteriza pela fragmentação da pobreza, e se configura como estratégia política de caráter neoliberal, pois ao invés de proporcionar a articulação entre os programas, adota o princípio da focalização. Apresenta, ainda, como características: o primeiro-damismo; a indefinição de recursos, já que depende dos recursos que são alocados em vários ministérios; a centralização no executivo federal; a prefeiturização em detrimento da descentralização; e o regresso às ações assistencialistas que descaracterizam a assistência social enquanto direito do cidadão (Silva, 2001).

Tais dados evidenciam como os recursos do orçamento fiscal destinados à Função Assistência são executados em uma diversidade de ações, cuja natureza assistencial é discutível. Evidentemente, muitas delas possuem interface com a política de assistência social, dada sua peculiaridade de política transversal. Mas, tais dados também indicam que recursos próprios da função assistência podem ser inadequadamente utilizados para financiar ações específicas de outras políticas, como é o caso das ações direcionadas para 
demarcação de área indígena, implantação de sistema sanitário e abastecimento de água em escolas, Instituto de Previdência dos Congressistas, entre outras. Se, por um lado, isto pode ser um elemento indicador de seu caráter ubíquo, também é revelador das dificuldades de sua definição, delimitação e precisão conceituai, o que a torna suscetível a desvios e descontrole político.

\section{Execução dos recursos destinados à Função Assistência Social procedentes do orçamento da seguridade social}

De acordo com a Constituição Federal, ao orçamento da seguridade social cabe financiar, exclusivamente, as ações das três políticas que a compõem. Contudo, também aqui foi observada uma pulverização de recursos desta esfera orçamentária em vários ministérios: da Agricultura, Abastecimento e Reforma Agrária, do Exército, da Justiça, da Integração Regional e do Planejamento e Orçamento.

Em 1994 e 1995, a LBA, extinta em 1995, e locus específico da assistência social à época, respondeu pelo maior montante de recursos executados. Consumiu, em 1994, R \$333 milhões (59\%) e, em 1995, ano de sua extinção, R\$ 299 milhões (36\%). Ainda em 1995, quando ocorreu o reordenamento institucional da área da assistência social, o Ministério do Planejamento e Orçamento, apesar de vir em segundo lugar na representação do montante executado, apresentou um percentual alto de $30 \%$, correspondente a $R \$ 248$ milhões.

Após sua implementação, o FNAS, que recebe recursos somente do orçamento da seguridade social, apresentou o maior montante e uma evolução crescente de recursos. Em seguida, os maiores executores dos recursos foram o Ministério do Planejamento e Orçamento, em 1996 e 1997, com R\$ 94 milhões (8\%) e R\$ 304 milhões (13\%) respectivamente; a Companhia Nacional de Abastecimento, em 1998, com R $\$ 324$ milhões (11\%), e a SUDENE com $\mathrm{R} \$ 367$ milhões (24\%), em 1999. É importante ressaltar que, inclusive, o Ministério da Previdência e Assistência Social recebeu parte destes recursos, mas estes não foram alocados no FNAS.

Em 2000 e 2001, a nova classificação eliminou várias unidades orçamentárias, mas a pulverização permaneceu. O Ministério da Previdência e Assistência Social consumiu aproximadamente o mesmo valor, o que correspondeu ao mesmo percentual em cada 
ano: $\mathrm{R} \$ 6$ milhões $(0,1 \%)$; a Companhia Nacional de Abastecimento absorveu $R \$ 93$ milhões (1,8\%) e $R \$ 49$ milhões $(0,9 \%)$, respectivamente; o Instituto Nacional de Seguro Social (INSS) recebeu $R \$ 1,7$ bilhão (34\%) em 2000, e em 2001 a ação sob sua responsabilidade passou para o Fundo de Regime Geral da Previdência Social, o qual foi responsável pela fatia de $R \$ 1,6$ bilhão $(31,3 \%)$.

A Tabela 4 sintetiza o percentual dos recursos executados pelo FNAS e pelas demais unidades orçamentárias provenientes da seguridade social, ou seja, excluindo do total os gastos provenientes do orçamento fiscal (o que já foi indicado na Tabela 2). Aqui, é possível notar mais claramente a evolução decrescente do percentual do FNAS em relação às demais unidades.

\section{Tabela 4 - Percentual do Orçamento da Seguridade Social Executado na Função Assistência Social pelo FNAS e Outras Unidades Orçamentárias-1996/2001}

\begin{tabular}{l|r|r|r|r|r|c}
\hline \multirow{2}{*}{ Unidades Orçamentárias } & \multicolumn{6}{|c}{ Ano } \\
\cline { 2 - 7 } & \multicolumn{1}{|c|}{1996} & 1997 & 1998 & 1999 & 2000 & 2001 \\
\hline FNAS & 85,40 & 81,05 & 85,08 & 67,37 & 63,88 & 67,80 \\
Outras Unidades Orçamentárias & 14,60 & 18,95 & 14,92 & 32,63 & 36,12 & 32,20 \\
TOTAL & 100,00 & 100,00 & 100,00 & 100,00 & 100,00 & 100,00 \\
\hline
\end{tabular}

Fonte: SIAFI/SIDOR disponibilizados pela DISOC/PEA. Elaboração própria.

O FNAS teve aumento em valores absolutos ao longo dos anos e sempre foi a unidade orçamentária que deteve o maior montante de recursos. Em 1996, consumiu $R \$ 938$ milhões; em 1998, $R \$ 2,3$ bilhões; em 2000, R \$ 3,2 bilhões e, em 2001, 3,5 bilhões. Contudo, identifica-se o decréscimo da participação percentual do FNAS em relação às demais unidades orçamentárias, sobretudo a partir de 1999, o que indica uma fuga de recursos da seguridade social para outros órgãos financiarem ações que não se caracterizam, necessariamente, como assistência social, como será visto a seguir, no detalhamento das ações. Com a criação do FNAS, conforme mostra a Tabela 5, não ocorreu a absorção das ações já existentes, à exceção dos serviços de ação continuada e das ações sociais e comunitárias. A análise seguinte contempla as ações implementadas 
por outras unidades orçamentárias, mesmo após a vigência do FNAS e no próximo item será feita uma análise exclusivamente das ações financiadas por este fundo.

\section{Tabela 5 - Recurso Federal do Orçamento da Seguridade Social Executado na Função Assistência Social por Ação sem os Recuros Alocados no FNAS -1994/2001}

\begin{tabular}{|c|c|c|c|c|c|c|c|c|}
\hline \multirow{2}{*}{ Ação } & \multicolumn{8}{|c|}{ Anos } \\
\hline & 1994 & 1995 & 1996 & 1997| & 1998 & 1999 & 2000 & 2001 \\
\hline Apoio à criança carente & 246.907 & 354.638 & \multicolumn{6}{|c|}{ Ação incorporada ao FNAS } \\
\hline Apoio ao cidadão, à família e ao deficiente & 54.941 & 99.272 & \multicolumn{6}{|c|}{ Ação incorporada ao FNAS } \\
\hline Apoio à pessoa idosa & 19.756 & 42.865 & \multicolumn{6}{|c|}{ Ação incorporada ao FNAS } \\
\hline $\begin{array}{l}\text { Desenvolvimento de ações sociais e } \\
\text { comunitárias }\end{array}$ & 4.535 & & \multicolumn{6}{|c|}{ Açãd incorporada ao FNAS } \\
\hline $\begin{array}{l}\text { Coordenação do sistema nacional de } \\
\text { defesa civi! }\end{array}$ & 28.739 & 248.852 & 94.535 & 304.883 & 53.564 & 95.637 & & \\
\hline $\begin{array}{l}\text { Coordenação das ações integradas de PPD* } \\
\text { à sociedade }\end{array}$ & 8.144 & 3.185 & 3.608 & 3.601 & 3.397 & 2.191 & & \\
\hline Manutenção da reabilitação profissional & 8.167 & 8.752 & 10.665 & 9.184 & 9.593 & 6.148 & & \\
\hline Manutenção do serviço social & 2.320 & 3.297 & 6.232 & 5.364 & 6.056 & 3.404 & & \\
\hline $\begin{array}{l}\text { Coordenação da política da criança e do } \\
\text { adolescente }\end{array}$ & 133.141 & 27.320 & 32.894 & 40.381 & 15.537 & 14.946 & & \\
\hline Distribuição emergencial de alimentos & 25.887 & 4.661 & & 69.524 & 106.574 & 179.844 & & \\
\hline Capacitação profissional & 3.485 & 1.858 & 474 & & & & & \\
\hline $\begin{array}{l}\text { Atividades a cargo do Instituto Nacional de } \\
\text { Seguro Social }\end{array}$ & 7.312 & 17.704 & & & & & & \\
\hline Apoio às ações comunitárias e as instituições & 11.440 & & & & & & & \\
\hline Conlribuição à fundos & 7.353 & & _ & & _ & . & & \\
\hline Coordenação e manutenção da ação social & & 10.459 & & & & & & \\
\hline $\begin{array}{l}\text { Implantação das ações de integração sócio } \\
\text { laboral de PPD' }\end{array}$ & & & 2.299 & 3.716 & & 851 & & \\
\hline $\begin{array}{l}\text { Programa de distribuição emergência! de } \\
\text { alimentos }\end{array}$ & & & 9.644 & & & & & \\
\hline $\begin{array}{l}\text { Distribuição emergencial de alimentos nd } \\
\text { polígono das secas }\end{array}$ & & & & & 218.008 & & & \\
\hline $\begin{array}{l}\text { Programa emergencial de frentes produtivas } \\
\text { no pol. das secas }\end{array}$ & & & & & & 404.051 & & \\
\hline $\begin{array}{l}\text { Supervisão e coordenação da política de } \\
\text { assistência social }\end{array}$ & & & & & 7.768 & 8.543 & & \\
\hline $\begin{array}{l}\text { Programa emergencial de combale aos efeitos } \\
\text { da seca }\end{array}$ & & & & & & 590.950 & & \\
\hline Pagamento de renda mensal vitalícia por idade & & & & & & & 654.877 & 604.500 \\
\hline $\begin{array}{l}\text { Pagamento de renda mensal vitalícia por } \\
\text { invalidez }\end{array}$ & & & & & & & 1.081 .696 & 1.011 .860 \\
\hline $\begin{array}{l}\text { Capacitação de conselheiros, gestores e } \\
\text { técncos de AS" }\end{array}$ & & & & & & & 558 & 1.089 \\
\hline $\begin{array}{l}\text { Aquisição de alimentos para distribuição } \\
\text { gratuita }\end{array}$ & & & & & & & 87.688 & 46.583 \\
\hline $\begin{array}{l}\text { Formulação de políticas na área de } \\
\text { assistência social }\end{array}$ & & & & & & & 6.132 & 5.281 \\
\hline TOTAL & 562.127 & 822.863 & 160.351 & 436.653 & 420.497 & 1.306 .565 & 1.830 .951 & 1.669 .313 \\
\hline
\end{tabular}

Fonte: SIAFI/SIDOR disponibilizados pela DISOC/IPEA. Em R $\$ 1.000,00$ a preços de dez/2001, deflacionados mês a mês pelo IGP-DI. Elaboração própria.

* Pessoa Portadora de Deficiência
"Assistência social

Ao analisar o período que antecede o FNAS, são identificadas, em 1994, as ações dos serviços de ação continuada ('apoio à criança carente', 'apoio ao cidadão, à família e ao deficiente' e 'apoio à pessoa idosa), como detentoras dos maiores montantes de recursos. Em 1995, a 'coordenação do sistema nacional de defesa civil', responsável pela defesa permanente contra as calamidades públicas e situações de emergência, como a seca e inundações, ficou com 
$30 \%$ dos recursos, atrás apenas da ação 'apoio à criança carente', que ficou com $43 \%$.

Estendendo a análise até 1999, quando o FNAS já estava implantado, os recursos da seguridade social executados fora deste fundo podem ser classificados em diferentes tipos de ações. O primeiro conjunto agrupa ações de caráter emergencial como 'coordenação do sistema nacional de defesa civil', 'programas de distribuição emergencial de alimentos', 'programas emergenciais de alimentos e de frentes produtivas no polígono da secas', 'programa emergencial de combate aos efeitos da seca'. O segundo conjunto engloba ações direcionadas aos segmentos criança, adolescente e portador de deficiência: 'coordenação da política de proteção à criança e ao adolescente', 'coordenação das ações integradas da pessoa portadora de deficiência', e 'ações de integração sócio-laboral do portador de deficiência'. O terceiro conjunto refere-se a ações de competência da previdência social: 'manutenção da reabilitação profissional', direcionada unicamente aos segurados em situação de incapacidade total ou parcial para o trabalho e às pessoas portadoras de deficiência, com vistas ao ingresso destes cidadãos no mercado de trabalho, apesar de a previdência não garantir os postos de emprego (Martins, 2000); 'manutenção do serviço social', destinada à garantia de acesso à informações aos beneficiários da previdência social, além de concessão da documentação necessária para a habilitação aos benefícios, bem como recursos materiais para atendimento de situações sociais de risco dos segurados do INSS (Martins, 2000).

Um quarto conjunto de ações intitula-se 'coordenação da política de assistência social', e encontra-se alojada no âmbito do MPAS. Embora o recurso não tenha sido alocado no FNAS, as atividades objetivavam acompanhar, normatizar e avaliar os planos, programas e projetos relativos à assistência social. Por fim, havia a ação denominada 'capacitação profissional' que, após a extinção do Ministério de Bem-Estar Social, foi transferida para o Ministério da Justiça e desenvolvia atividades de capacitação dos recursos humanos com vistas ao aprimoramento dos serviços prestados à pessoa portadora de deficiência.

Em 2000 e 2001, a nova classificação orçamentária permite maior detalhamento e constata-se que ocorreu a exclusão da maioria das ações até então pulverizadas em vários ministérios, com exceção das ações direcionadas para a distribuição de alimentos a famílias 
carentes. Por outro lado, ocorreu a inclusão de três novas ações implementadas com recursos da seguridade social sem passar pelo FNAS: o 'pagamento da renda mensal vitalícia', a 'capacitação de gestores, conselheiros e técnicos da assistência social' e a 'formulação de políticas na área'.

Observe-se que a 'renda mensal vitalícia' (RMV) recebeu $R \$$ 1,7 bilhão em 2000 e $R \$ 1,6$ bilhão em 2001, absorvendo a maior fatia dos recursos da seguridade social executados fora do FNAS. Após a implantação do Benefício de Prestação Continuada, a RMV está sendo gradativamente extinta, mas ainda beneficia os cidadãos que adquiriram este direito antes de 1993. A RMV é um benefício assistencial, que integra a política de previdência, sendo vedada sua acumulação com qualquer benefício previdenciário. Era devida às pessoas maiores de 70 anos ou pessoa portadora de deficiência "que não exercessem atividade remunerada, não auferindo qualquer rendimento superior ao valor de sua renda mensal, nem fossem mantidos por pessoa de quem dependessem obrigatoriamente, não tendo outro meio de prover o próprio sustento" (Martins, 2000, p. 474). No entanto, este benefício tem um caráter contributivo na medida em que, além dos critérios expostos acima, para receber a RMV o cidadão deveria cumprir uma das condições a seguir: ter sido filiado à previdência em qualquer época, durante 12 meses seguidos ou somando todos os períodos; ter exercido durante cinco anos, no mínimo, qualquer atividade atualmente incluída na previdência; ou ter começado a contribuir para a previdência depois dos 60 anos (MPAS, 1997, 1998).

A pulverização de recursos em ações com as orientações explicitadas acima deveriam ter os recursos melhor otimizados, na perspectiva de ampliar as ações assistenciais e de disponibilizar para a população maior acesso aos serviços públicos. Tal dispersão impede uma gestão financeira transparente, permite a aplicação de recursos em ações assistenciais sem o devido acompanhamento e controle do CNAS e favorece o paralelismo e o assistencialismo no uso dos recursos públicos.

Delimitando ainda mais o foco de análise, será abordado a seguir o recurso executado pelo FNAS. Já foi constatado que este fundo apresentou um aumento crescente de recursos, mas é preciso identificar como se deu a distribuição dos mesmos entre as ações.

Quando foi instituída, em 1974, a RMV correspondia à metade do salário mínimo e, após a Constituição de 1988, este benefício passou a ser de um salário mínimo. 


\section{Execução dos recursos destinados à Função Assistência Social pelo FNAS}

A ampliação global da execução orçamentária do FNAS não significou aumento de recursos alocados para todas as ações. De modo geral, no período de 1996 a 2001, o governo deu continuidade às ações direcionadas para o atendimento a crianças, pessoas idosas e pessoas portadoras de deficiência, o que aponta o caráter focalizado nos segmentos tidos como incapazes para o trabalho.

\section{Tabela 6 - Recurso Federal do Orçamento da Assistência Social Executado no Âmbito do FNAS por Ação - 1996/2001}

\begin{tabular}{|c|c|c|c|c|c|c|}
\hline \multirow{2}{*}{ Ação } & \multicolumn{6}{|c|}{ Ano } \\
\hline & 1996 & 1997 & 1998 & 1999 & 2000 & 2001 \\
\hline Apoio à criança carente & 310.516 & 332.031 & 318.747 & 286.539 & 307.216 & 271.701 \\
\hline Apoio ao cidadão, à família e ao deficiente & 89.183 & 88.973 & 88.551 & 85.222 & 79.953 & 85.328 \\
\hline Apoio à pessoa idosa & 37.073 & 39.596 & 38.433 & 36.281 & 45.521 & 43.241 \\
\hline $\begin{array}{l}\text { Ações de geração de renda no } \\
\text { enfrentamento à pobreza }\end{array}$ & 283.908 & 50.463 & 49.323 & 9.084 & 28.154 & 35.960 \\
\hline Ações sociais comunitárias & 8.218 & 17.768 & 55.500 & 34.450 & 58.437 & 73.606 \\
\hline $\begin{array}{l}\text { Programa de erradicação ao trabalho } \\
\text { infanto-juvenil }\end{array}$ & & 22.841 & 57.879 & 105.568 & 204.240 & 318.077 \\
\hline $\begin{array}{l}\text { Assistência à criança e ao adolescente no } \\
\text { enfrentamento à pobreza }\end{array}$ & & 124.819 & 125.484 & 61.032 & & \\
\hline $\begin{array}{l}\text { Assistência às famílias carentes no } \\
\text { enfrentamento à pobreza }\end{array}$ & & 132 & - & & - & \\
\hline $\begin{array}{l}\text { Participação da União em programas de } \\
\text { renda mínima }\end{array}$ & . & - & - & 48.837 & 186.359 & \\
\hline Combate à exploração sexual infanto-juvenil & & & & & 5.741 & 6.516 \\
\hline $\begin{array}{l}\text { Atendimento à criança e ao adolescente em } \\
\text { abrigo }\end{array}$ & & & & & 15.157 & 13.796 \\
\hline $\begin{array}{l}\text { Implantação do sistema de monitoramento e } \\
\text { avaliação da assistência social }\end{array}$ & & & & & 1.085 & 477 \\
\hline Implantação de centros da juventude & & & & & 7.918 & 3.399 \\
\hline Agente jovem & & & - & & - & 27.691 \\
\hline Implantação de portais do projeto Alvorada & - & - & - & - & - & 10.911 \\
\hline Implantação de NAF's" & - & - & & & - & 8.074 \\
\hline $\begin{array}{l}\text { Capacitação de liderança comunitária para } \\
\text { o combate da violência }\end{array}$ & - & - & - & . & - & 4.855 \\
\hline TOTAL SEM 0 BPC & 728.898 & 676.623 & 733.917 & 667.013 & 939.781 & 903.632; \\
\hline Benefício de prestação continuada & 209.179 & 1.192 .041 & 1.663 .327 & 2.007 .063 & 2.292 .224 & 2.592 .275 \\
\hline Revisão e auditoria dos BPCs* & & - & & 23.708 & 10.885 & 2.796 \\
\hline Processamento de dados do $\mathrm{BPC}^{\star}$ & - & - & & - & 3.312 & 4.266 \\
\hline Concessão e cessação de BPCs* & & & & & 3.344 & 1.339 \\
\hline $\begin{array}{l}\text { Remuneração dos agentes pagadores de } \\
\text { BPCs }{ }^{*}\end{array}$ & & & & - & & 16.680 \\
\hline TOTAL COM 0 BPC & 938.077 & 1.868 .664 & 2.397 .244 & 2.648 .952 & 3.249 .546 & 3.520 .988 \\
\hline
\end{tabular}


Em relação aos dados da Tabela $6,^{8}$ o que mais chama a atenção são os totais a que se chega com ou sem a inclusão do BPC. É claramente visível que o crescimento dos recursos do FNAS deveu-se quase que exclusivamente a este benefício. Quando o BPC não é contabilizado, verifica-se que este período caracterizou-se por oscilações crescentes e decrescentes, com leve aumento dos recursos de $R \$ 728$ milhões, em 1996, para $R \$ 903$ milhões, em 2001. Observando o percentual de crescimento destes recursos temse uma redução de $7 \%$ de 1996 para 1997, acréscimo de $8 \%$ em 1998, diminuição de $9 \%$ para 1999, aumento de $40 \%$ em 2000 e decréscimo de $3 \%$ em 2001.

Esta oscilação permite concluir a inconstância dos valores assegurados para os serviços, programas e projetos financiados pelo FNAS. A exceção permanece sendo o BPC. Constata-se a redução nos valores executados nos serviços de ação continuada, exceto o 'apoio à pessoa idosa'. O 'apoio à criança carente' consumiu $R \$ 310$ milhões em 1996, reduzido para $R \$ 271$ milhões em 2001; o 'apoio ao cidadão, à família e ao deficiente,' em 1996, apresentou uma execução de $R \$ 89$ milhões, diminuindo para $R \$ 85$ milhões em 2001 ; e o 'apoio à pessoa idosa', contrariando a tendência decrescente, apresentou um aumento dos recursos de $\mathrm{R} \$ 37$ milhões em 1996 para $\mathrm{R} \$ 43$ milhões em 2001.

Em 1999, ocorreu a redução de recursos das ações dos serviços de ação continuada, dos projetos de enfrentamento à pobreza e das ações sociais comunitárias. A redução efetivada nesse ano só não foi maior devido à implementação do programa de renda mínima vinculado à educação (PGRM, atual bolsa-escola) e ao aumento dos recursos para o 'programa de erradicação ao trabalho infantil (PETI), o que permite interpretar que foi adotado um redirecionamento dos recursos para estas duas ações.

O aumento dos recursos, em 2000, deveu-se aos montantes direcionados aos dois programas citados (PGRM e PETI), além da inclusão de novas ações voltadas para a juventude (atendimento à criança e ao adolescente em abrigo e implantação de centros da juventude) e do gerenciamento do Abrigo Cristo Redentor, antes sob gestão do Estado do Rio de Janeiro.

${ }^{8}$ Os dados referentes ao FNAS foram publicados e analisados, no período 1996-2000, no livro de Ivanete Boschetti, Assistência Social no Brasil: um direito entre originalidade e conservadorismo. Os montantes apresentam pequenas diferenças porque no livro os valores analisados são nominais e neste trabalho os mesmos estão deflacionados pelo IGP-DI, a preços de dezembro de 2001. 
Em 2001, houve nova redução no total dos recursos aplicados nas ações, excluindo-se o BPC. É interessante observar que nesse ano o programa de renda mínima (bolsa-escola) deixou de ser financiado com recursos do FNAS, o que provocou um leve aumento dos recursos para os serviços de ação continuada, para o PETI e para os projetos de enfrentamento à pobreza, além da implementação de novas ações (agente jovem, NAF e Projeto Alvorada). Tal constatação reforça a afirmação anterior de que a utilização dos recursos do FNAS para o PGRM provocou a redução de recursos na rede $S A C$.

A Tabela 6 ressalta a evidente concentração dos recursos no BPC, juntamente com suas ações de caráter administrativo (revisão e auditoria, processamento de dados e serviços de concessão e cessação dos BPCs) que, a partir de 1997, consumiu a maior fatia de recursos em todos os anos, aumentando de $22 \%$, em 1996, para $75 \%$, em 1999, e $74 \%$, em 2001 , em relação ao orçamento do FNAS nestes anos.

\section{Considerações finais}

O neoliberalismo tem como característica central subjugar as políticas sociais às políticas monetaristas e de estabilização fiscal (Navarro, 1998). Seguindo este receituário, a ação governamental brasileira, ao implementar os dispositivos legais para a concretização da seguridade social, não se pautou pelo fortalecimento e ampliação dos direitos previstos. Ao contrário, diversas medidas provisórias foram publicadas autoritariamente, reduzindo o escopo das políticas de saúde, previdência e assistência (Pereira, 2002).

O orçamento da seguridade social foi pensado como um espaço de financiamento integrado das políticas de saúde, previdência e assistência social. Entretanto, este se configura mais como um espaço de disputa de recursos entre estas políticas, em vez de constituir-se como campo de articulação. Esta disputa não deve ser atribuída à falsa idéia de incongruência entre a base de custeio e as ações previstas na seguridade social, isto é, de uma previsão de recursos insuficientes para financiar ações "excessivas" de proteção social. A insuficiência dos recursos da seguridade social para manter os direitos assegurados constitucionalmente deve-se, sim, a outros fatores, entre os quais a realocação dos recursos do orçamento da seguridade social para o pagamento dos juros da dívida pública; a 
utilização das contribuições sociais como COFINS, CPMF, CSLL para outros destinos, reduzindo o recurso da seguridade social; a reduzida participação do orçamento fiscal no orçamento da seguridade, conforme previsto na Constituição; a isenção ou renúncia fiscal a muitas entidades que não se caracterizam como de assistência social; a sonegação fiscal; a reduzida capacidade contributiva da maioria dos trabalhadores, em face dos baixos salários e, sobretudo, uma política econômica que não ataca o problema do mercado informal, o que gera enormes fugas de recursos da seguridade e leva milhares de trabalhadores a não ter acesso aos direitos previdenciários (Boschetti, 2003).

Outro aspecto a ser enfatizado é a atitude do governo federal de obstruir a materialização de um dos aspectos centrais para o financiamento: a descentralização dos recursos. A esfera federal, na contramão desta diretriz, tratou de expandir a carga tributária incidente sobre as fontes de receita que não são partilhadas com as esferas locais, as quais são constituídas fundamentalmente pelas contribuições sociais e compõem maioritariamente o orçamento da seguridade (Dain, 1995; Varsano et al., 2001). Como justificativa da União para privilegiar estas fontes de financiamento, foi alegada a necessidade de ampliação de recursos para o custeio da seguridade social, mas os recursos obtidos foram destinados essencialmente para pagamento de juros e rolagem da dívida pública. A descentralização, então, se caracterizou pela transferência de encargos para as esferas locais, sem o equivalente repasse de recursos para manutenção das políticas sociais, sobretudo da assistência social.

Ao se discutir estratégias de descentralização, é imprescindível considerar as formas de financiamento. A descentralização envolve precisamente a questão de redistribuição de poder, deslocamento de centros decisórios, como também o correspondente repasse de recursos. Mas da forma como vem se consolidando no Brasil, a descentralização vem assumindo o caráter de transferência de responsabilidade e servindo mais para o propósito da privatização e redução dos recursos do que fortalecimento do poder local (Arretche, 1997). Com a posição submissa do país à economia mundial estabelecida pelo $\mathrm{FMI}$, tem-se uma política tributária cada vez mais regressiva. Não se institui o imposto sobre as grandes fortunas, não se investe na fiscalização e cobrança dos sonegadores e, como se não bastasse, ainda são reduzidos os impostos sobre a renda do capital produtivo e especulativo. 
O reconhecimento da assistência social como direito social deuse sob o ideário neoliberal, em momento de reorientação das políticas sociais, o que limitou sua consolidação como política pública e dever do Estado. Sua condição de direito social está condicionada à reorganização do quadro institucional. No entanto, a classificação orçamentária não incorporou as inovações ocorridas neste campo e permanecem várias ações não específicas classificadas na função assistência social, desenvolvidas por várias unidades orçamentárias com recursos provenientes do orçamento fiscal e da seguridade social.

É notável a imprecisão conceituai quanto às ações da assistência social na classificação funcional. E possível eleger pelo menos quatro tipos de problemas decorrentes desta imprecisão: ações assistenciais desenvolvidas por vários ministérios, sem relação com o sistema descentralizado e participativo previsto na LOAS; ações cujo caráter assistencialista é evidente e que, ao serem inseridas nesta função, afrontam a perspectiva da assistência como direito de cidadania; ações que, claramente, não possuem caráter assistencial mas absorvem recursos da função assistência; e, por fim, ações típicas da assistência, relacionadas diretamente à LOAS, mas cujos recursos não estão alocados no FNAS.

Mesmo após a reorganização da classificação, não ocorreu a alocação de recursos para ações específicas de assistência social na sua correspondente função orçamentária. Não foi erradicada a pulverização de recursos da seguridade social nas unidades orçamentárias, os quais não são alocados no FNAS. É importante ressaltar que no ano 2000 e 2001, a renda mensal vitalícia, com $34 \%$ e $45 \%$, e o benefício de prestação continuada, com $31 \%$ e $50 \%$, respectivamente, foram responsáveis pela absorção da maior fatia de recursos da função assistência. Somados, estes dois benefícios de transferência de renda correspondem a $79 \%$, em 2000 , e $81 \%$, em 2001, dos recursos da seguridade social destinados à função assistência social.

Considerando que a assistência encontra-se presente, explícita ou implicitamente, em praticamente todas as políticas sociais, tornase pertinente e imprescindível discutir a problemática da imprecisão conceituai desta política na área do planejamento governamental. Isto porque os equívocos conceituais, deliberados ou não, permitem a pulverização dos já parcos recursos em ações que não se caracterizam como assistência social. 
Bibliografia

ANDERSON, Perry. Balanço do neoliberalismo. In: SADER, E.; GENTILI, P. (orgs.). Pós-neoliberalismo: as políticas sociais e o Estado democrático. Rio de Janeiro: Paz e Terra, 1995.

ANFP (Associação Nacional de Auditores Fiscais da Previdência Social). Análise da seguridade social em 2001. Brasília: ANFIP, 2002. (Mimeogr.).

ARRETCHE, Marta. O sistema de proteção social brasileiro. São Paulo em Perspectiva, São Paulo, v. 11, n. 3, 1997.

BIONDI, Aloysio. O Brasil privatizado: um balanço do desmonte do Estado. São Paulo: Fundação Perseu Abramo, 1999.

BOSCHETTI, Ivanete. Assistência Social no Brasil: um Direito entre originalidade e conservadorismo. Brasília: GESST/SER/UnB, 2001.

A reforma da previdência e a seguridade social brasileira. In: MORHY, Lauro (Org.). Reforma da Previdência em questão. Brasília: Ed. UnB, 2003.

CORDEIRO, José Lucas. Gasto Federal em Assistência Social e suas fontes de financiamento. Serviço Social e Sociedade, São Paulo, n. 62, 2000.

CORREIO BRAZILIENSE, 26 jul. 2002, p. 8.

CUNHA, Rosani E. da. O financiamento de políticas socais no Brasil. In: PROGRAMA DE CAPACITACCÃO CONTINUADA PARA ASSISTENTES SOCIAIS. Módulo 3: As Políticas Sociais. Brasília:CEAD-UnB/CFESS/ ABEPSS, 2000.

DAIN, Sulamis; SOARES, Laura T. Reforma do Estado e políticas públicas: relacões intergovernamentais e descentralização desde 1988. In: PROGRAMA DE CAPACITAĈ̃O DE GESTORES DE POLÍTICAS DE EMPREGO. Reforma do Estado \& políticas de emprego no Brasil. São Paulo: UNICAMP, 1998.

DAIN, Sulamis. Seguridade e Previdência: um drama em fascículos. Revista Inscrita, Rio de Janeiro, n. 2, 1998.

FARIAS, Pedro C. L. de. A seguridade social no Brasil e os obstáculos institucionais à sua implementação. Brasília: MARE/ENAP, 1997. (Cadernos ENAP n' 11).

FRAGA, Eugênio. A DRU e as receitas sociais vinculadas. Revista de Conjuntura, Brasília: CORECON-DF, 2000.

LESBAUPIN, Ivo (Org). O desmonte da nação: balanço do governo FHC. Rio de Janeiro: Vozes, 2000.

MARTINS, Sérgio P. Direito da Seguridade Social. São Paulo: Atlas, 2000. 
MELO, Austregésilo. Proposta de lei orçamentária para 2002 prioriza pagamento da dívida. 2001. Nota Técnica n. 54. Disponível em $<$ www.inesc.org.br $>$.

MIRANDA, Sérgio. Construção da LDO e Orçamento para o ano 2000. In: BRASIL. Ministério da Previdência e Assistência Social. Conselho Nacional de Assistência Social. Co-financiamento da Assistência Social: anais da Reunião Ampliada ocorrida em Salvador, 19 e 20 ago. 1999.

NAVARRO, Vincenç. Neoliberalismo y Estado del Bienestar. Barcelona: Ariel, 1998.

PAIVA, Beatriz A.; ROCHA, Paulo E. O financiamento da política de assistência social em perspectiva. Serviço Social e Sociedade, São Paulo, n. 68, 2001.

PEREIRA, Potyara A. P. A assistência social na perspectiva dos direitos: crítica aos padrões dominantes de proteção aos pobres no Brasil. Brasília: Thesaurus, 1996.

As interfaces da Assistência Social: reflexões sobre a política de transporte no Brasil. Comunicação apresentada no GEIPOT/Empresa Brasileira de Planejamento de Transportes - Ministério dos Transportes, em Brasília, no dia 21 ago. 1998.

. A questão social e as transformações das políticas sociais: respostas do Estado e da Sociedade Civil. Ser Social, Brasília, n. 6, 2000.

Política de assistência social no Brasil: avanços e retrocessos. Brasília: NEPPOS/CEAM/UnB, 2002.( Cadernos do CEAM. n. 11)

PISCITELLI, Roberto B., TIMBÓ, Maria Zulene R; ROSA, Maria Berenice. Contabilidade pública: uma abordagem da administração financeira pública. São Paulo: Atlas, 2002.

RIBEIRO, José A.; FERNANDES, Maria Alice. Acompanhamento e dimensionamento do gasto social federal: considerações metodológicas e resultados gerais para os anos 90. Revista Políticas Sociais: Acompanhamento e Análise, Brasília, n. 1, 2000.

SALVADOR, Evilásio; BOSCHETTI, Ivanete. A reforma da Previdência Social no Brasil e os impactos sobre o mercado de trabalho. Serviço Social e Sociedade, São Paulo, n. 70, jul. 2002.

SILVA, Maria Ozanira e Silva (Coord.). O Comunidade Solidária: o nãoenfrentamento da pobreza no Brasil. São Paulo: Cortez, 2001.

SOARES, Laura T. Os custos sociais do ajuste neoliberal na América Latina. São Paulo: Cortez, 2000.

SPOSATI, Aldaíza et al. A assistência na trajetória das políticas sociais brasileiras: uma questão em análise. São Paulo: Cortez, 1998. 
TEIXEIRA, I. B. Quem são os 'primos pobres' do orçamento? Cadernos ABONG: Os Gastos Públicos Federais com as Políticas Sociais, Série Especial II, produzida pela ABONG e CNAS como subsídio à $2^{a}$ Conferência Nacional de Assistência Social, Brasília, 1997.

TEIXEIRA, Sandra Oliveira. Fragmentação do gasto federal com Assistência Social. Brasília, 2002. Monografia. Departamento de Serviço Social, Universidade de Brasília.

TOURAINE, Alain. O campo político de FHC. Tempo Social: Revista de Sociologia da USP, São Paulo, n.2, 2000.

VARSANO, Ricardo et ai. Substituindo o PIS e a COFINS - e por que não a CPMF? - por uma contribuição não-cumulativa. Brasília: IPEA, 2001. (Mimeogr.).

\section{Documentos}

BRASIL Constituição da República Federativa do Brasil. Brasília: Senado Federal, 1988.

BRASLL Ministério da Previdência e Assistência Social. Secretaria de Estado de Assistência Social. Lei Orgânica de Assistência Social. DOU, Brasília, 7 dez. 1993.

BRASLL Ministério da Previdência e Assistência Social. Secretaria de Estado de Assistência Social. Política Nacional de Assistência Social. DOU, Brasília,16 abr. 1999.

BRASIL Ministério da Previdência e Assistência Social. Secretaria de Estado de Assistência Social. Norma Operacional Básica de Assistência Social. DOU, Brasília, 16 abr. 1999.

BRASIL Ministério do Planejamento, Orçamento e Gestão. Secretaria de Orçamento Federal. Manual Técnico de Orçamento: instruções para a elaboração da proposta orçamentária da União para 1999, MTO-02. Brasília: Imprensa Nacional, 1998.

BRASLL Ministério do Planejamento, Orçamento e Gestão. Secretaria de Orçamento Federal. Manual Técnico de Orçamento: instruções para a elaboração da proposta orçamentária da União para 2001, MTO-02. Brasília: Imprensa Nacional, 2000.

BRASIL Senado Federal. Consultoria de Orçamentos, Fiscalização e Controle. Planos e Orçamentos Públicos: Conceitos, Elementos Básicos e Resumo dos Projetos de Leis do Plano Plurianual/2000-2003 e do Orçamento/ 2001. Internet, fev. 2001. 
TEIXEIRA, I. B. Quem são os 'primos pobres' do orçamento? Cadernos ABONG: Os Gastos Públicos Federais com as Políticas Sociais, Série Especial II, produzida pela ABONG e CNAS como subsídio à $2^{a}$ Conferência Nacional de Assistência Social, Brasília, 1997.

TEIXEIRA, Sandra Oliveira. Fragmentação do gasto federal com Assistência Social. Brasília, 2002. Monografia. Departamento de Serviço Social, Universidade de Brasília.

TOURAINE, Alain. O campo político de FHC. Tempo Social: Revista de Sociologia da USP, São Paulo, n.2, 2000.

VARSANO, Ricardo et ai. Substituindo o PIS e a COFINS - e por que não a CPMF? - por uma contribuição não-cumulativa. Brasília: IPEA, 2001. (Mimeogr.).

Documentos

BRASIL Constituição da República Federativa do Brasil. Brasília: Senado Federal, 1988.

BRASIL Ministério da Previdência e Assistência Social. Secretaria de Estado de Assistência Social. Lei Orgânica de Assistência Social. DOU, Brasília, 7 dez. 1993.

BRASIL Ministério da Previdência e Assistência Social. Secretaria de Estado de Assistência Social. Política Nacional de Assistência Social. DOU, Brasília, 16 abr. 1999.

BRASIL Ministério da Previdência e Assistência Social. Secretaria de Estado de Assistência Social. Norma Operacional Básica de Assistência Social. DOU, Brasília, 16 abr. 1999.

BRASIL Ministério do Planejamento, Orçamento e Gestão. Secretaria de Orçamento Federal. Manual Técnico de Orçamento: instruções para a elaboração da proposta orçamentária da União para 1999, MTO-02. Brasília: Imprensa Nacional, 1998.

BRASIL Ministério do Planejamento, Orçamento e Gestão. Secretaria de Orçamento Federal. Manual Técnico de Orçamento: instruções para a elaboração da proposta orçamentária da União para 2001, MTO-02. Brasília: Imprensa Nacional, 2000.

BRASIL Senado Federal. Consultoria de Orçamentos, Fiscalização e Controle. Planos e Orçamentos Públicos: Conceitos, Elementos Básicos e Resumo dos Projetos de Leis do Plano Plurianual/2000-2003 e do Orçamento/ 2001. Internet, fev. 2001. 